\title{
Early administration of fibrinogen concentrate is associated with improved survival among severe trauma patients: a single-centre propensity score-matched analysis
}

Yuki Itagaki ${ }^{*}$ (DD Mineji Hayakawa², Kunihiko Maekawa², Tomoyo Saito², Akira Kodate ${ }^{1}$, Yoshinori Honma², Asumi Mizugaki ${ }^{2}$, Tomonao Yoshida², Takayoshi Ohyasu'², Kenichi Katabami and Takeshi Wada²

\begin{abstract}
Background: Fibrinogen plays an important role in haemostasis during the early phase of trauma, and low fibrinogen levels after severe trauma are associated with haemostatic impairment, massive bleeding, and poor outcomes. Aggressive fibrinogen supplementation may improve haemostatic function, as fibrinogen levels deteriorate before other routine coagulation parameters in this setting. Therefore, we evaluated whether early administration of fibrinogen concentrate $(F C)$ was associated with improved survival in severe trauma patients.

Methods: This single-centre retrospective study evaluated patients with severe trauma (injury severity score $\geq 16$ ) who were admitted to our emergency department between January 2010 and July 2018. The exclusion criteria included age $<18$ years, cardiac arrest before emergency department arrival, cervical spinal cord injury not caused by a high-energy accident, and severe burn injuries. The FC and control groups included trauma patients who received and did not receive FC within $1 \mathrm{~h}$ after emergency department arrival, respectively. Propensity scores were used to balance the two groups based on the trauma and injury severity score (TRISS), heart rate at emergency department admission, and age. The primary outcome was the in-hospital survival rate.

Results: The propensity scoring model had a c-statistic of 0.734 , the Hosmer-Lemeshow chi-squared value was 7.036 (degrees of freedom $=8$ ), and the non-significant $p$ value of 0.533 indicated a good model fit. The propensity score matching created 31 matched pairs of patients, who had appropriately balanced characteristics. The FC group had a significantly higher in-hospital survival rate than the control group (log-rank $p=0.013$ ). The FC group also used significantly higher amounts of red blood cells and fresh frozen plasma within $6 \mathrm{~h}$ after emergency department admission. However, the two groups had similar transfusion amounts between 6 and $24 \mathrm{~h}$ after emergency department admission.

Conclusions: The present study revealed that early FC administration was associated with a favourable survival rate among severe trauma patients. Therefore, FC may be useful for the early management of trauma-induced coagulopathy and may improve outcomes in this setting.
\end{abstract}

Keywords: Cryoprecipitate, Fibrinogen, Fibrinogen concentrate, Fresh frozen plasma, Trauma-induced coagulopathy

\footnotetext{
*Correspondence: koaraninaritaizo@gmail.com

'Emergency and Critical Care Center, Sapporo City General Hospital, 1-1

Nishi13, Kita 11, Kita-ku, Sapporo, Hokkaido 060-8604, Japan

Full list of author information is available at the end of the article
}

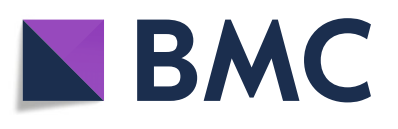

(C) The Author(s). 2020 Open Access This article is distributed under the terms of the Creative Commons Attribution 4.0 International License (http://creativecommons.org/licenses/by/4.0/), which permits unrestricted use, distribution, and reproduction in any medium, provided you give appropriate credit to the original author(s) and the source, provide a link to the Creative Commons license, and indicate if changes were made. The Creative Commons Public Domain Dedication waiver (http://creativecommons.org/publicdomain/zero/1.0/) applies to the data made available in this article, unless otherwise stated. 


\section{Background}

Trauma remains a major cause of death $[1,2]$, which is primarily related to uncontrolled bleeding during the early phase of trauma [3]. Traumatic haemorrhage may be exacerbated by coagulopathy (i.e. trauma-induced coagulopathy). Although the pathophysiology of traumainduced coagulopathy remains incompletely understood [4-8], we speculate that it is generated by the following mechanisms: (1) coagulation activation, (2) hyperfibrino(geno)lysis, and (3) consumption coagulopathy [5, 6]. Coagulation activation caused by massive tissue injuries cause excessive thrombin generation, which leads to the fibrinogen consumption. Hyperfibrino(geno)lysis is caused by the acute release of tissue-plasminogen activator, which is induced by tissue hypoperfusion and massive tissue injuries-induced coagulation activation. Various coagulation factors and platelets are consumed by coagulation activation and hyperfibrino(geno)lysis. Nevertheless, trauma-induced coagulopathy is often clearly present on emergency department (ED) arrival and is associated with massive haemorrhage, increased transfusion needs, and a high mortality rate [9-14]. Unfortunately, in patients with severe trauma, haemostatic impairment is worsened by haemodilution, hypothermia, and acidosis during the early phases of treatment $[5,7,15,16]$. Therefore, better management of trauma-induced coagulopathy is needed to improve the outcomes of these patients.

Fibrinogen plays an important role in haemostasis during the early phase of trauma [16-22], as low fibrinogen levels impair the firmness of the fibrin clots that help to control haemostasis. Fibrinogen also accelerates platelet aggregation $[6,23,24]$, and many studies have indicated that low fibrinogen levels at ED arrival are associated with haemostatic impairment, massive bleeding, and poor outcomes in patients with severe trauma [11-14, 16, 24-28]. Furthermore, fibrinogen levels deteriorate faster than other haemostatic components during the early phase of severe trauma $[6,11,27,29]$. Therefore, decreased fibrinogen levels are an important marker for trauma-induced coagulopathy, and fibrinogen supplementation is needed to help maintain haemostatic function $[6,16]$. Recent European guidelines have suggested that fibrinogen concentrations should be maintained at $>1.5-2.0 \mathrm{~g} / \mathrm{L}$ in patients with severe trauma [30], and there is increasing awareness that fibrinogen concentrate (FC) can be effective for managing massive haemorrhage in these patients. Fibrinogen supplementation can be achieved by using fresh frozen plasma (FFP) and cryoprecipitate [31]. However, FFP must be thawed via a time-consuming process [32], and ABO compatibility must be confirmed before administering FFP [33]. Certain trauma centres have recently begun early coagulation factor supplementation using pre-thawed FFP; however, thawed plasma has a short shelf-life and must be discarded if it is not used [34]. While cryoprecipitate contains factor VIII, factor XIII, and von Willebrand factor (unlike FC), cryoprecipitate also requires thawing before administration [26] and carries a risk of viral infection, similar to FFP $[35,36]$. Therefore, although aggressive fibrinogen replacement therapy using FFP or cryoprecipitate provides favourable outcomes [17, 37], this benefit must be balanced with the immediate availability and rapid administration of $\mathrm{FC}$, which does not require thawing or confirmation of $\mathrm{ABO}$ compatibility [38]. Furthermore, FC administration may increase plasma fibrinogen levels more easily than FFP [31] and may produce a greater increase in fibrinogen levels more rapidly than both FFP and cryoprecipitate [39].

Several reports have indicated that FC administration is effective for patients with severe trauma [18, 38, 40, 41]. For instance, Wafaisade et al. retrospectively examined the effects of FC administration and reported that it helped improve the short- and not long-term mortality rate [18]. Nevertheless, their FC group included patients who were treated in the ED and intensive care unit; this partially obscured the effects of early FC administration [18]. A single-centre randomised controlled trial (RCT) using realtime thromboelastometry also revealed that relative to FFP, coagulation factor concentrates (including FC, prothrombin complex concentrate, and factor XIII concentrate) helped improve outcomes in patients with severe trauma [41]. However, that trial failed to clarify how the patients' outcomes varied according to the use of FC, prothrombin complex concentrate, and factor XIII concentrate [41]. Akbari et al. also performed a single-centre RCT and reported that patients with severe trauma who received FC had a significantly lower mortality rate and shorter duration of hospitalisation than those who received FFP and the control group [38]. However, that report failed to clearly describe the timing of FC administration [38]. Therefore, to the best of our knowledge, no studies have specifically examined the early administration of FC in patients with severe trauma. The present study aimed to determine whether this strategy improved survival, based on a propensity score-matched analysis.

\section{Methods}

\section{Patient selection and data collection}

This single-centre retrospective study evaluated electronic medical records from a tertiary emergency and critical care centre (Hokkaido University Hospital). The study protocol was approved by our institutional review board, and the requirement for informed consent was waived owing to the retrospective design.

Adult patients with severe trauma (injury severity score $\geq 16$ ) who were directory admitted to our ED between January 2010 and July 2018 were eligible for inclusion. Patients were excluded based on the following criteria: (a) age < 18 years, (b) cardiac arrest before ED arrival, (c) cervical spinal cord injury not caused by a 
high-energy accident, and (d) severe burn injuries. The records of eligible patients were searched to collect data regarding trauma severity, laboratory test results from ED arrival, clinical characteristics, treatments, transfusion amounts, and patient outcomes.

\section{Definitions}

The patients were divided into an FC group (received FC within $1 \mathrm{~h}$ after ED arrival) and a control group (no FC or FC received at $1-24 \mathrm{~h}$ after ED arrival). The decision to administer FC, its timing, and the FC amount were fully at the discretion of the attending physicians. The administered FC was commercially available freezedried human fibrinogen (Fibrinogen HT i.v. $1 \mathrm{~g}$ "JB", Japan Blood Products Organization, Tokyo, Japan). On sub-group analysis, severe brain injury was defined as injury with a head abbreviated injury scale (AIS) of $\geq 3$.

\section{Statistical analysis}

Propensity score matching was used to balance the groups' characteristics and clinical variables. The propensity scores for early FC administration were estimated using a logistic regression model, based on the trauma and injury severity score, heart rate at ED admission, and age, all of which are related to the early administration of FC. Patients with and without early FC administration were then matched 1:1 based on their propensity scores, using the nearest neighbour method without replacement, and a calliper width of 0.2 standardised deviations for the propensity score. We used the standardised difference to evaluate the covariate balances after the propensity score matching, with absolute standardised differences of $>0.1$ considered indicative of a meaningful imbalance. The two groups were then compared using the Mann-Whitney $U$ and chi-squared tests, as appropriate. In-hospital survival outcomes were compared using the Kaplan-Meier method and log-rank tests.

In the two sub-groups, namely, patients with blunt trauma and with severe brain injury, additional analyses were performed using the same methods.

All analyses were performed using SPSS software (version 25; IBM Japan, Tokyo, Japan). All reported $p$ values were two-tailed, and differences were considered statistically significant at $p$ values of $<0.05$.

\section{Results}

During the study period, 480 patients with severe trauma were directly transferred to our ED from the accident site. After the exclusion of ineligible patients, 148 eligible patients were divided into the FC group (38 patients) and the control group (110 patients) (Fig. 1). The patients' overall characteristics are shown in Table 1; it shows that the FC group had a significantly higher critical status on ED admission. The FC group included trauma patients who received FC within $1 \mathrm{~h}$ after ED arrival $(n=38)$, and the control group included 110

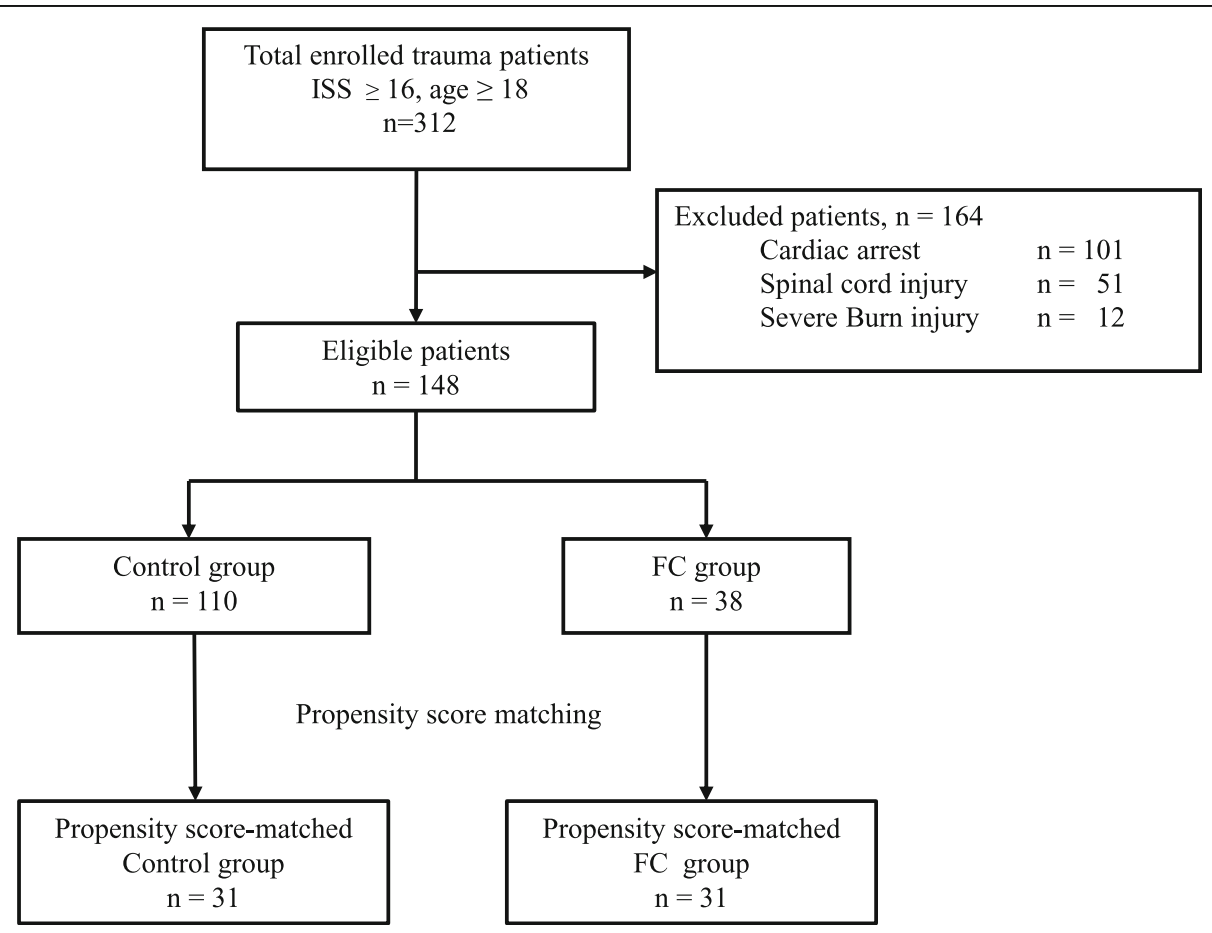

Fig. 1 Study flowchart. The fibrinogen concentrate (FC) group included trauma patients who received FC within $1 \mathrm{~h}$ after their emergency department admission. The control group included patients who did not receive FC within $1 \mathrm{~h}$ after emergency department admission. ISS, injury severity score 
Table 1 Characteristics of the patients

\begin{tabular}{|c|c|c|c|}
\hline & $\begin{array}{l}\text { Control group } \\
n=110\end{array}$ & $\begin{array}{l}\text { FC group } \\
n=38\end{array}$ & $p$ value \\
\hline Age (year) & $54(39-71)$ & $53(32-72)$ & 0.565 \\
\hline Gender, male & $86(78.2 \%)$ & $20(52.6 \%)$ & 0.005 \\
\hline Blunt trauma & $106(96.4 \%)$ & $36(94.7 \%)$ & 0.647 \\
\hline \multicolumn{4}{|l|}{ Mechanism of the injury } \\
\hline Traffic accident (in the car) & 29 (26.4\%) & $13(4.2 \%)$ & \multirow[t]{6}{*}{0.313} \\
\hline Traffic accident (pedestrian) & $29(26.4 \%)$ & $13(34.2 \%)$ & \\
\hline Fall & 39 (35.5\%) & $10(26.3 \%)$ & \\
\hline Invert & $6(5.5 \%)$ & $0(0.0 \%)$ & \\
\hline Stab wound/cutting & $3(2.7 \%)$ & $2(5.3 \%)$ & \\
\hline Others & $4(3.6 \%)$ & $0(0.0 \%)$ & \\
\hline \multicolumn{4}{|l|}{ Injury to the admission to ED } \\
\hline $0-30$ (min) & $12(10.9 \%)$ & $9(23.7 \%)$ & \multirow[t]{4}{*}{0.138} \\
\hline $30-60(\min )$ & $64(58.2 \%)$ & $21(55.3 \%)$ & \\
\hline 60-90 (min) & $21(19.1 \%)$ & $3(7.9 \%)$ & \\
\hline $90-(\min )$ & $13(11.8 \%)$ & $5(13.2 \%)$ & \\
\hline Revised trauma score & $6.72(5.03-7.84)$ & $5.68(4.09-6.08)$ & $<0.001$ \\
\hline Probability of survival & $0.842(0.630-0.943)$ & $0.567(0.230-0.832)$ & $<0.001$ \\
\hline \multicolumn{4}{|l|}{ Vital signs on the admission to ED } \\
\hline Heart rate (per min) & $86(72-105)$ & $110(86-120)$ & 0.010 \\
\hline Glasgow Coma Scale & $11(6-14)$ & $6(3-13)$ & 0.035 \\
\hline Systolic Blood Pressure (mmHg) & $120(99-151)$ & $93(68-137)$ & 0.014 \\
\hline Respiratory rate (per min) & $22(16-25)$ & $21(17-30)$ & 0.489 \\
\hline Injury severity score & $25(20-32)$ & $34(25-41)$ & $<0.001$ \\
\hline \multicolumn{4}{|l|}{ Abbreviated injury scale } \\
\hline Head/neck & $4(1-5)$ & $4(0-5)$ & 0.264 \\
\hline Als face & $0(0-0)$ & $0(0-1)$ & 0.482 \\
\hline AlS chest & $3(0-4)$ & $3(0-4)$ & 0.104 \\
\hline AlS abdomen & $0(0-2)$ & $0(0-3)$ & 0.065 \\
\hline AIS extremity & $1(0-3)$ & $2(0-3)$ & 0.047 \\
\hline AIS external & $1(0-1)$ & $1(0-1)$ & 0.082 \\
\hline \multicolumn{4}{|l|}{ Blood gas analysis } \\
\hline $\mathrm{pH}$ & $7.35(7.30-7.38)$ & $7.24(7.11-7.35)$ & $<0.001$ \\
\hline Base deficit (mmol/L) & $2.5(0.3-5.4)$ & $6.95(2.7-14.63)$ & $<0.001$ \\
\hline Lactate (mmol/L) & $3.2(2.3-4.7)$ & $5.8(3.6-10.0)$ & $<0.001$ \\
\hline \multicolumn{4}{|l|}{ Laboratory tests } \\
\hline Platelet $\left(\times 10^{3} / \mu \mathrm{L}\right)$ & $200(147-235)$ & $193(146-234)$ & 0.632 \\
\hline PT-INR & $1.06(0.98-1.158)$ & $1.22(1.12-1.40)$ & $<0.001$ \\
\hline Fibrinogen (mg/dL) & $193(159-235)$ & $156(137-219)$ & 0.034 \\
\hline $\mathrm{FDP}(\mu \mathrm{g} / \mathrm{mL})$ & $76.4(30.0-165.0)$ & $99.5(45.0-188.0)$ & 0.349 \\
\hline D-dimer ( $\mu \mathrm{g} / \mathrm{mL})$ & $47.8(19.5-104.2)$ & $58.3(28.3-104.9)$ & 0.633 \\
\hline
\end{tabular}

FC fibrinogen concentrate, ED emergency department, AIS abbreviated injury scale, PT-INR prothrombin time-international normalised ratio, FDP fibrin/fibrinogen degradation products 
patients who did not receive FC within $1 \mathrm{~h}$ after ED arrival (39/110 received FC within 1-24h after admission and 71/110 did not receive FC).

The propensity score model had a $c$-statistic of 0.734 , which indicated good discrimination between the patients assigned to the FC and control groups. The HosmerLemeshow chi-squared value was 7.036 (degrees of freedom $=8$ ), and the non-significant $p$ value of 0.533 indicated a good model fit. The propensity score matching process ultimately selected 31 patients from each group, and the characteristics of the matched patients are shown in Table 2. The two groups had generally well-balanced characteristics including the probability of survival, which provides a comprehensive assessment of trauma severity. Most imbalanced variables were more severe in the FC group than in the control group.

Figure 2 shows the matched groups' Kaplan-Meier survival curves. The FC group had a significantly higher inhospital survival rate $(\log$-rank $p=0.013)$ and a significantly lower 28-day in-hospital mortality rate (6/31 patients [19.3\%] vs. $14 / 31$ patients [45\%], $p=0.03$ ). During the first 28 days, $16 \%$ of patients in the FC group (5/31 patients) had died owing to a brain injury, which was not significantly lower than the $32 \%$ rate in the control group (10/31 patients). The rates of haemorrhage-related deaths in the FC and control groups were $0 \%(0 / 31$ patients) and 6\% (2/ 31 patients), respectively.

Table 3 shows the haemostatic treatments and transfusion requirements in the matched groups, which revealed that the two groups had similar frequencies of haemostatic interventions. The two groups had similar amounts of total FC during the first $24 \mathrm{~h}$ after ED admission ( $p=$ 0.96). The FC group had higher transfusion amounts during the first $6 \mathrm{~h}$ after ED admission; however, no significant inter-group differences were observed between 6 and $24 \mathrm{~h}$ after ED admission.

In patients with blunt trauma $(n=142)$, the propensity score matching process ultimately selected 29 patients from each group (Additional file 1: Table S1), and the FC group had a significantly higher survival rate than the control group $(p=0.034)$ (Additional file 2: Figure S1). We additionally analysed patients with severe brain injury (head AIS $\geq 3, n=97$ ). The propensity score matching process ultimately selected 20 patients from each group (Additional file 1: Table S2); the FC group tended to have a higher survival rate than the control group; however, the difference lacked statistical significance $(p=0.174)$ (Additional file 2: Figure S2.).

\section{Discussion}

The present study is the first to indicate that early FC administration $(<1 \mathrm{~h}$ after ED admission) may be useful for patients with severe trauma, based on a propensity score-matched analysis. Many studies have indicated that low fibrinogen levels at ED arrival are associated with haemostatic impairment, massive bleeding, and poor outcomes in patients with severe trauma [11-14, 16, 24-28]. Therefore, early fibrinogen supplementation will help manage trauma-induced coagulopathy [16-22].

Fibrinogen levels deteriorate faster than other haemostatic components during the early phase of severe trauma $[6,11,27,29]$, and early fibrinogen supplementation is crucial for maintaining haemostatic function [16]. In this context, two RCTs have examined the feasibility of early FC administration [39, 42]. Nascimento et al. performed a single-centre RCT that examined FC administration within $50 \mathrm{~min}$ after ED admission of patients with severe trauma, and concluded that this approach helped increase plasma fibrinogen levels; however, they acknowledged the need for larger RCTs [42]. However, a second multicentre RCT examined FC administration within $45 \mathrm{~min}$ after ED admission in patients with severe trauma, and found that this approach was not feasible as only $69 \%$ of the patients received the intervention within $45 \mathrm{~min}$ (versus an intended proportion of $90 \%$ of patients receiving the early intervention) [39]. Interestingly, both trials were granted a waiver for obtaining informed consent by the relevant ethics committees [39, 42]. However, if an RCT is planned to evaluate the effects of early FC administration for patients with severe trauma, the same non-consent process may not be approved in other regions including Japan. The present study revealed that early FC administration can easily be performed within $1 \mathrm{~h}$, and was associated with a favourable survival rate after severe trauma in a real clinical setting. Moreover, the FC and control groups had used similar total amounts of FC during the first $24 \mathrm{~h}$ after ED admission; however, delayed FC administration (i.e. at 1-24 $\mathrm{h}$ after ED admission) was not associated with the same improvement in severe trauma outcomes.

Several previous reports have indicated that FC administration provides various advantages in patients with severe trauma [18, 38, 40, 41]; however, those studies did not specifically examine the time point(s) for FC administration. In our centre, FFP is mainly used for the supplementation of coagulation factors in patients with severe trauma. In addition, FC can be used before starting the FFP administration and/or to boost the fibrinogen levels during FFP administration. Therefore, we evaluated the effects of early FC administration in this setting, which revealed fairly clear advantages for this early treatment strategy.

Although the difference was not significant, we observed that the FC group had approximately one-half the number of brain injury-related deaths in the control group. Furthermore, on sub-group analysis of patients with severe brain injury, although there were no significant differences, we observed that early FC administration tended to improve 
Table 2 Characteristics of the propensity score-matched patients

\begin{tabular}{|c|c|c|c|c|}
\hline & $\begin{array}{l}\text { Control group } \\
n=31\end{array}$ & $\begin{array}{l}\text { FC group } \\
n=31\end{array}$ & Matched standardised difference & $p$ value \\
\hline Age (years) & $55(36-72)$ & $53(32-74)$ & -0.006 & 0.978 \\
\hline Gender, male & $25(80.6)$ & $19(61.3)$ & -0.435 & 0.093 \\
\hline Blunt trauma & $29(93.5 \%)$ & $29(93.5 \%)$ & $<0.001$ & 1.000 \\
\hline \multicolumn{5}{|l|}{ Mechanism of the injury } \\
\hline Traffic accident (in the car) & $12(38.7 \%)$ & $12(38.7 \%)$ & $<0.001$ & \multirow[t]{6}{*}{1.000} \\
\hline Traffic accident (pedestrian) & $11(35.5 \%)$ & $11(35.5 \%)$ & $<0.001$ & \\
\hline Fall & 6 19.4\%) & 6 19.4\%) & $<0.001$ & \\
\hline Invert & $0(0.0 \%)$ & $0(0.0 \%)$ & $<0.001$ & \\
\hline Stab wound/cutting & $2(6.5 \%)$ & $2(6.5 \%)$ & $<0.001$ & \\
\hline Others & $0(0.0 \%)$ & $0(0.0 \%)$ & $<0.001$ & \\
\hline \multicolumn{5}{|l|}{ Injury to the admission to the ED } \\
\hline $0-30(\min )$ & $6(19.3 \%)$ & $6(19.3 \%)$ & $<0.001$ & \multirow[t]{4}{*}{0.963} \\
\hline 30-60 (min) & $18(58.0 \%)$ & $18(58.0 \%)$ & $<0.001$ & \\
\hline 60-90 (min) & $4(12.9 \%)$ & $3(9.67 \%)$ & -0.102 & \\
\hline $90-(\min )$ & $3(9.67 \%)$ & $4(12.9 \%)$ & 0.102 & \\
\hline Revised trauma score & $5.03(4.09-6.90)$ & $5.68(4.45-6.38)$ & 0.086 & 0.750 \\
\hline Probability of survival & $0.684(0.276-0.878)$ & $0.724(0.275-0.886)$ & 0.043 & 0.894 \\
\hline \multicolumn{5}{|l|}{ Vital signs on the admission to ED } \\
\hline Heart rate (per min) & $94(68-120)$ & $105(80-120)$ & 0.119 & 0.578 \\
\hline Glasgow coma scale & $6(3-13)$ & $7(4-14)$ & 0.271 & 0.228 \\
\hline Systolic Blood Pressure $(\mathrm{mmHg})$ & $112(91-150)$ & $100(70-140)$ & -0.135 & 0.383 \\
\hline Respiratory rate (per min) & $19(16-24)$ & $24(16-30)$ & 0.459 & 0.105 \\
\hline Injury severity score & $30(21-36)$ & $34(25-41)$ & 0.353 & 0.182 \\
\hline AlS head and neck & $4(0-5)$ & $4(0-5)$ & 0.016 & 0.895 \\
\hline AIS face & $0(0-0)$ & $0(0-1)$ & -0.403 & 0.414 \\
\hline AIS chest & $3(0-4)$ & $3(0-4)$ & -0.164 & 0.699 \\
\hline AIS abdomen & $0(0-2)$ & $0(0-3)$ & 0.660 & 0.087 \\
\hline AIS extremity & $1(0-3)$ & $2(0-3)$ & -0.295 & 0.668 \\
\hline AIS external & $1(0-1)$ & $1(0-1)$ & 0.419 & 0.678 \\
\hline \multicolumn{5}{|l|}{ Blood gas analysis } \\
\hline $\mathrm{pH}$ & $7.33(7.24-7.37)$ & $7.25(7.15-7.35)$ & -0.283 & 0.095 \\
\hline Base deficit (mmol/L) & $3.7(2.1-6.7)$ & $6.3(2.4-12.5)$ & -0.343 & 0.130 \\
\hline Lactate (mmol/L) & $4.1(2.9-5.5)$ & $4.9(3.0-7.9)$ & 0.219 & 0.260 \\
\hline \multicolumn{5}{|l|}{ Laboratory data } \\
\hline Platelet $\left(\times 10^{3} / \mu \mathrm{L}\right)$ & $208(163-240)$ & $193(114-235)$ & -0.158 & 0.559 \\
\hline PT-INR & $1.08(1.03-1.27)$ & $1.20(1.10-1.40)$ & -0.158 & 0.078 \\
\hline Fibrinogen (mg/dL) & 169 (124-200) & 164 (138-219) & 0.113 & 0.647 \\
\hline $\mathrm{FDP}(\mu \mathrm{g} / \mathrm{mL})$ & $120.0(66.6-267.0)$ & $93.5(43.0-188.0)$ & 0.082 & 0.391 \\
\hline D-dimer $(\mu \mathrm{g} / \mathrm{mL})$ & $67.5(46.5-207.7)$ & $56.9(20.4-125.0)$ & -0.019 & 0.240 \\
\hline
\end{tabular}

FC fibrinogen concentrate, ED emergency department, AIS Abbreviated Injury Scale, PT-INR prothrombin time-international normalised ratio, FDP fibrin/fibrinogen degradation products

the survival rate of the patients. In patients with severe brain injury, hyperfibrinolysis is frequently observed at admission to the ED [43, 44]; this contributes to enlargement of intracranial haematomas, trauma-induced coagulopathy, and poor outcomes [43, 45-47]. In this context, FC may help restore haemostasis by complementing plasma 


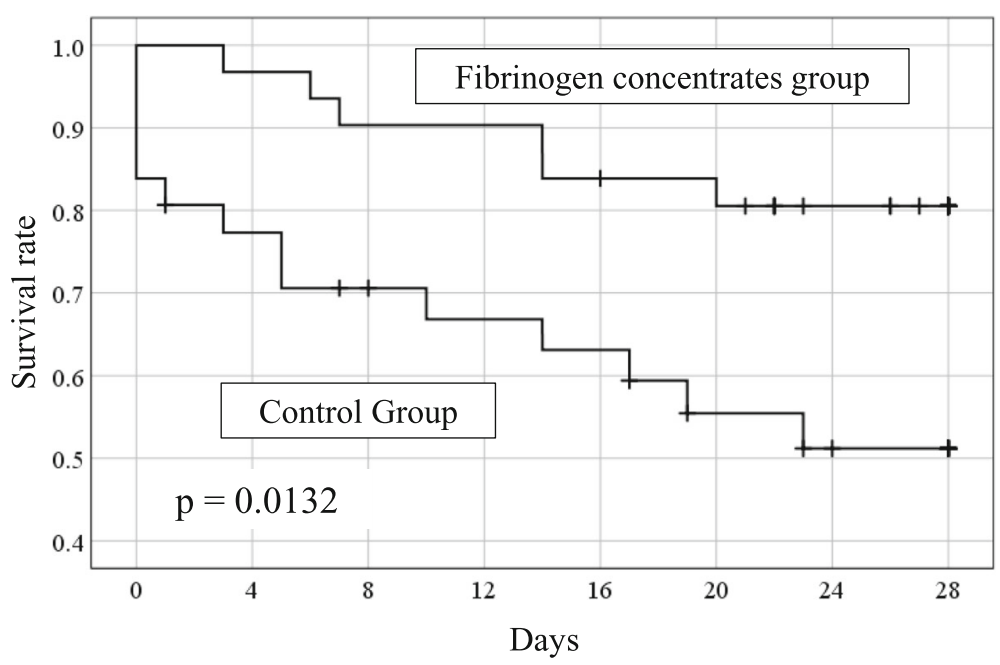

Fig. 2 Kaplan-Meier curves for the fibrinogen concentrate (FC) and control groups

Table 3 Hemostatic treatments and transfusion amounts in the propensity-matched groups

\begin{tabular}{|c|c|c|c|}
\hline & $\begin{array}{l}\text { Control group } \\
n=31\end{array}$ & $\begin{array}{l}\text { FC group } \\
n=31\end{array}$ & $p$ value \\
\hline Interventions to emergency haemostasis & $5(16.1 \%)$ & $10(32.2 \%)$ & 0.138 \\
\hline Thoracotomy and/or laparotomy & $3(9.7 \%)$ & $8(25.8 \%)$ & 0.096 \\
\hline Transarterial embolization & $3(9.7 \%)$ & $2(6.5 \%)$ & 0.641 \\
\hline Other emergency interventions & $10(32.2 \%)$ & $14(45.1 \%)$ & 0.297 \\
\hline Craniotomy & $8(25.8 \%) *$ & $9(29.0 \%)$ & 0.753 \\
\hline Orthopaedic surgery & $2(6.5 \%)$ & $4(9.7 \%)$ & 0.390 \\
\hline Other & $0(0.0 \%)$ & $2(9.7 \%)$ & 0.151 \\
\hline \multicolumn{4}{|l|}{ Transfusion } \\
\hline \multicolumn{4}{|l|}{ During the first $6 \mathrm{~h}$ after the admission to ED } \\
\hline RBC (unit) & $2(0-10)$ & $8(2-22)$ & 0.016 \\
\hline FFP (unit) & $4(0-10)$ & $14(4-23)$ & 0.009 \\
\hline PC (unit) & $0(0-0)$ & $0(0-20)$ & 0.059 \\
\hline \multicolumn{4}{|l|}{ From 6 to $24 \mathrm{~h}$ after the admission to ED } \\
\hline RBC (unit) & $0(0-4)$ & $2(0-5)$ & 0.387 \\
\hline FFP (unit) & $0(0-7)$ & $4(0-9)$ & 0.133 \\
\hline PC (unit) & $0(0-15)$ & $0(0-20)$ & 0.771 \\
\hline FC administration during $24 \mathrm{~h}$ after the admission to ED & 19 (61.2\%) & $31(100 \%)$ & $<0.001$ \\
\hline \multicolumn{4}{|l|}{ First FC administration after the admission to ED } \\
\hline $0-1 \mathrm{~h}$ & 0 & $31(100 \%)$ & $<0.001$ \\
\hline $1-3 h$ & $10(32.2 \%)$ & $0(0.0 \%)$ & \\
\hline $3-24 h$ & $9(29.0 \%)$ & $0(0.0 \%)$ & \\
\hline Total amounts during $24 \mathrm{~h}$ after the admission to ED & $3(3-3)$ & $3(3-3)$ & 0.96 \\
\hline
\end{tabular}

${ }^{*}$ A patients who has performed burr hole surgery was included

$F C$ fibrinogen concentrate, $E D$ emergency department, $R B C$ red blood cell, FFP fresh frozen plasma, $P C$ platelet concentrate 
fibrinogen, which deteriorates owing to hyperfibrinolysis in patients with severe brain injury. Therefore, FC supplementation may suppress intracranial haematoma enlargement and reduce the risk of death owing to severe brain injury.

In situations with severe bleeding, Geeraedts et al. have suggested that "blind" coagulation management (without point-of-care guidance, such as thromboelastometry) underestimates the real demand for coagulation factors [48]. However, based on the severe decrease in plasma fibrinogen levels during the early phase of severe trauma, we empirically administer FC based on trauma severity alone, before confirming the laboratory test results. Thus, we intentionally "overestimate" the demand for fibrinogen; this is in contrast with the finding reported by Geeraedts et al., who stated that this approach naturally underestimates demand. Although Schöchl et al. have reported the utility of point-of-care guidance [32], the use of FC and its timing in the present study were totally dependent on the attending physicians' discretion. Therefore, although our "blind" coagulation management using FC without point-of-care guidance may "overestimate" the demand for $\mathrm{FC}$ in severe trauma cases, we were still able to effectively administer FC earlier than if we had relied on point-of-care guidance.

In the present study, the FC group had significantly higher amounts of transfusions during the first $6 \mathrm{~h}$ after ED arrival, although the FC and control groups had similar total amounts of transfusions (RBC, FFP, and $\mathrm{PC}$ ) between $6 \mathrm{~h}$ and $24 \mathrm{~h}$ after ED arrival. Furthermore, the patients in FC group were more recently treated than those in the control groups (this data has not been presented). Therefore, the higher transfusion amounts during the first $6 \mathrm{~h}$ and recent advanced treatments may have affected the survival rate in the FC group. Nevertheless, we speculate that the FC may have helped prevent early trauma-related deaths, which may have increased the total need for transfusions in the FC group, thereby introducing the so-called "survival bias".

The present study has several limitations. The most important limitation is the small number of patients enrolled. The second is the single-centre retrospective study design; however, all eligible patients had available data regarding all variables from ED admission and before FC administration. Third, although we used propensity scores to balance the groups' characteristics, some variables remained imbalanced. However, it is important to note that most imbalanced variables were more severe in the FC group (vs. the control group); this suggests that FC may have improved the survival ratio even in relatively severe cases. Fourth, the demand for transfusions during the first $6 \mathrm{~h}$ of admission to the ED was increased in the FC group. We considered that this result may have been affected by two possible causes, namely, survival bias and recent advances in trauma care. This limitation has been mentioned previously. Therefore, a multi-centre RCT is needed to address these limitations; a planned RCT aiming to identify the optimal timing and dose of fibrinogen supplementation during trauma resuscitation will be of particular value [33].

\section{Conclusions}

The present study revealed a favourable survival rate after early FC administration in patients with severe trauma. In this setting, FC may be an ideal early treatment for managing trauma-induced coagulopathy and may help improve patient outcomes.

\section{Supplementary information}

Supplementary information accompanies this paper at https://doi.org/10. 1186/s13017-020-0291-9.

Additional file 1: Table S1. Characteristics of the propensity score matched patients with blunt trauma. Table S2. Characteristics of the propensity score matched patients with severe traumatic

Additional file 2: Figure S1. Kaplan-Meier curves for the fibrinogen concentrate $(\mathrm{FC})$ and control groups in the pair-matched blunt trauma patients. Figure S2. Kaplan-Meier curves for the fibrinogen concentrate (FC) and control groups in the pair-matched severe head trauma patients

\section{Abbreviations}

AIS: Abbreviated Injury Scale; FC: Fibrinogen concentrate; ED: Emergency department; RBC: Red blood cell; FFP: Fresh frozen plasma; PC: Platelet concentrate

\section{Acknowledgements}

We thank Editage (www.editage.com) for English language editing.

\section{Authors' contributions}

$\mathrm{YI}$ collected and interpreted the data and drafted the manuscript. $\mathrm{MH}$ conceived the study, analysed and interpreted the data, and drafted the manuscript. KM, TS, AK, YH, AM, TY, TO, KK, and TW read the manuscript and revised it for important intellectual content. All authors read and approved the final manuscript.

\section{Funding}

None

Availability of data and materials

All relevant data are presented in the published manuscript.

Ethics approval and consent to participate

The retrospective protocol of this study was approved by our institutional review board, and the requirement for informed consent was waived.

Consent for publication

Not applicable

\section{Competing interests}

The authors declare that they have no competing interests.

\section{Author details}

${ }^{1}$ Emergency and Critical Care Center, Sapporo City General Hospital, 1-1 Nishi13, Kita 11, Kita-ku, Sapporo, Hokkaido 060-8604, Japan. ²Department of Emergency Medicine, Hokkaido University Hospital, Sapporo, Japan. 
Received: 22 October 2019 Accepted: 6 January 2020 Published online: 14 January 2020

\section{References}

1. Naghavi M, Abajobir AA, Abbafati C, Abbas KM, Abd-Allah F, Abera SF, Aboyans V, Adetokunboh O, Afshin A, Agrawal A, et al. Global, regional, and national age-sex specific mortality for 264 causes of death, 1980-2016: a systematic analysis for the Global Burden of Disease Study 2016. Lancet. 2017:390(10100):1151-210.

2. Yeboah D, Mock C, Karikari P, Agyei-Baffour P, Donkor P, Ebel B. Minimizing preventable trauma deaths in a limited-resource setting: a test-case of a multidisciplinary panel review approach at the Komfo Anokye Teaching Hospital in Ghana. World J Surg. 2014;38(7):1707-12.

3. Kauvar DS, Wade CE. The epidemiology and modern management of traumatic hemorrhage: US and international perspectives. Crit Care. 2005; 9(Suppl 5):S1-9.

4. Gando S. Acute coagulopathy of trauma shock and coagulopathy of trauma: a rebuttal. You are now going down the wrong path. J Trauma. 2009;67(2):381-3.

5. Hayakawa M. Pathophysiology of trauma-induced coagulopathy: disseminated intravascular coagulation with the fibrinolytic phenotype. J Intensive Care. 2017;5(1):14

6. Hayakawa M. Dynamics of fibrinogen in acute phases of trauma. J Intensive Care. 2017:5(1):3.

7. Gando S, Hayakawa M. Pathophysiology of trauma-induced coagulopathy and management of critical bleeding requiring massive transfusion. Semin Thromb Hemost. 2016;42(2):155-65.

8. Gando S, Wada H, Thachil J. Scientific Standardization Committee on DIC of the International Society on Thrombosis and Haemostasis: differentiating disseminated intravascular coagulation (DIC) with the fibrinolytic phenotype from coagulopathy of trauma and acute coagulopathy of trauma-shock (COT/ACOTS). J Thromb Haemost. 2013;11(5):826-35.

9. Brohi K, Cohen MJ, Davenport RA. Acute coagulopathy of trauma: mechanism, identification and effect. Curr Opin Crit Care. 2007;13(6):680-5

10. Brohi K, Cohen MJ, Ganter MT, Schultz MJ, Levi M, Mackersie RC, Pittet JF. Acute coagulopathy of trauma: hypoperfusion induces systemic anticoagulation and hyperfibrinolysis. J Trauma. 2008;64(5):1211-7 discussion 1217

11. Hayakawa M, Gando S, Ono Y, Wada T, Yanagida Y, Sawamura A. Fibrinogen level deteriorates before other routine coagulation parameters and massive transfusion in the early phase of severe trauma: a retrospective observational study. Semin Thromb Hemost. 2015;41(1):35-42.

12. Sawamura A, Hayakawa M, Gando S, Kubota N, Sugano M, Wada T, Katabami K. Disseminated intravascular coagulation with a fibrinolytic phenotype at an early phase of trauma predicts mortality. Thromb Res. 2009;124(5):608-13.

13. Nakamura $Y$, Ishikura $H$, Kushimoto $S$, Kiyomi F, Kato H, Sasaki J, Ogura H, Matsuoka T, Uejima T, Morimura N, et al. Fibrinogen level on admission is a predictor for massive transfusion in patients with severe blunt trauma: analyses of a retrospective multicentre observational study. Injury. 2017; 48(3):674-9

14. Hayakawa M, Maekawa K, Kushimoto S, Kato H, Sasaki J, Ogura H, Matauoka T, Uejima T, Morimura N, Ishikura H, et al. High D-dimer levels predict a poor outcome in patients with severe trauma, even with high fibrinogen levels on arrival: a multicenter retrospective study. Shock. 2016:45(3):308-14.

15. Engstrom $M$, Schott $U$, Romner $B$, Reinstrup P. Acidosis impairs the coagulation: a thromboelastographic study. J Trauma. 2006;61(3):624-8.

16. Fries $D$, Martini WZ. Role of fibrinogen in trauma-induced coagulopathy. $\mathrm{Br} J$ Anaesth. 2010;105(2):116-21.

17. Stinger HK, Spinella PC, Perkins JG, Grathwohl KW, Salinas J, Martini WZ, Hess JR, Dubick MA, Simon CD, Beekley AC, et al. The ratio of fibrinogen to red cells transfused affects survival in casualties receiving massive transfusions at an army combat support hospital. J Trauma. 2008:64(2 Suppl):S79-85 discussion S85

18. Wafaisade A, Lefering R, Maegele M, Brockamp T, Mutschler M, Lendemans S, Banerjee M, Bouillon B, Probst C. Trauma Registry of DGU: Administration of fibrinogen concentrate in exsanguinating trauma patients is associated with improved survival at 6 hours but not at discharge. J Trauma Acute Care Surg. 2013;74(2):387-3 discussion 393-385.
19. Ranucci M, Solomon C. Supplementation of fibrinogen in acquired bleeding disorders: experience, evidence, guidelines, and licences. Br J Anaesth. 2012; 109(2):135-7.

20. Levy JH, Szlam F, Tanaka KA, Sniecienski RM. Fibrinogen and hemostasis: a primary hemostatic target for the management of acquired bleeding. Anesth Analg. 2012;114(2):261-74.

21. Nienaber U, Innerhofer P, Westermann I, Schochl H, Attal R, Breitkopf R, Maegele $M$. The impact of fresh frozen plasma vs coagulation factor concentrates on morbidity and mortality in trauma-associated haemorrhage and massive transfusion. Injury. 2011;42(7):697-701.

22. Meyer MA, Ostrowski SR, Windelov NA, Johansson PI. Fibrinogen concentrates for bleeding trauma patients: what is the evidence? Vox Sang. 2011;101(3):185-90.

23. Levy JH, Welsby I, Goodnough LT. Fibrinogen as a therapeutic target for bleeding: a review of critical levels and replacement therapy. Transfusion. 2014;54(5):1389-405 quiz 1388.

24. Schöchl H, Cotton B, Inaba K, Nienaber U, Fischer H, Voelckel W, Solomon C. FIBTEM provides early prediction of massive transfusion in trauma. Crit Care. 2011;15(6):R265.

25. Inaba K, Karamanos E, Lustenberger T, Schochl H, Shulman I, Nelson J, Rhee P, Talving P, Lam L, Demetriades D. Impact of fibrinogen levels on outcomes after acute injury in patients requiring a massive transfusion. $J$ Am Coll Surg. 2013;216(2):290-7.

26. Rourke C, Curry N, Khan S, Taylor R, Raza I, Davenport R, Stanworth S, Brohi K. Fibrinogen levels during trauma hemorrhage, response to replacement therapy, and association with patient outcomes. J Thromb Haemost. 2012; 10(7):1342-51.

27. Floccard B, Rugeri L, Faure A, Saint Denis M, Boyle EM, Peguet O, Levrat A, Guillaume C, Marcotte G, Vulliez A, et al. Early coagulopathy in trauma patients: an on-scene and hospital admission study. Injury. 2012;43(1):26-32.

28. Chambers LA, Chow SJ, Shaffer LE. Frequency and characteristics of coagulopathy in trauma patients treated with a low- or high-plasmacontent massive transfusion protocol. Am J Clin Pathol. 2011;136(3):364-70.

29. Hiippala S. Replacement of massive blood loss. Vox Sang. 1998;74(Suppl 2): 399-407.

30. Spahn DR, Bouillon B, Cerny V, Duranteau J, Filipescu D, Hunt BJ, Komadina R, Maegele M, Nardi G, Riddez L, et al. The European guideline on management of major bleeding and coagulopathy following trauma: fifth edition. Crit Care. 2019;23(1):98.

31. Collins PW, Solomon C, Sutor K, Crispin D, Hochleitner G, Rizoli S, Schochl H, Schreiber M, Ranucci M. Theoretical modelling of fibrinogen supplementation with therapeutic plasma, cryoprecipitate, or fibrinogen concentrate. Br J Anaesth. 2014;113(4):585-95.

32. Schöchl H. Goal-directed coagulation management of major trauma patients using thromboelastometry (ROTEM $\left.{ }^{\oplus}\right)$-guided administration of fibrinogen concentrate and prothrombin complex concentrate. Crit Care. 2010;14:R55.

33. Winearls J, Wullschleger M, Wake E, Hurn C, Furyk J, Ryan G, Trout M, Walsham J, Holley A, Cohen J, et al. Fibrinogen Early In Severe Trauma studY (FEISTY): study protocol for a randomised controlled trial. Trials. 2017; 18(1):241.

34. Schöchl H, Nienaber U, Maegele M, et al. Transfusion in traumathromboelastometry-guided coagulation factor concentrate-based therapy versus standard fresh frozen plasma-based therapy. Critical Care. 2011;15:R83.

35. Nascimento B, Goodnough LT, Levy JH. Cryoprecipitate therapy. Br J Anaesth. 2014;113(6):922-34

36. Schlimp CJ: Impact of fibrinogen concentrate alone or with prothrombin complex concentrate (+/- fresh frozen plasma) on plasma fibrinogen level and fibrin-based clot strength (FIBTEM) in major trauma: a retrospective study. Scandinavian Journal of Trauma, Resuscitation and Emergency Medicine 2013.

37. Holcomb JB, Tilley BC, Baraniuk S, Fox EE, Wade CE, Podbielski JM, del Junco DJ, Brasel KJ, Bulger EM, Callcut RA, et al. Transfusion of plasma, platelets, and red blood cells in a 1:1:1 vs a 1:1:2 ratio and mortality in patients with severe trauma: the PROPPR randomized clinical trial. JAMA. 2015;313(5):471-82.

38. Akbari $\mathrm{E}$, Safari $\mathrm{S}$, Hatamabadi $\mathrm{H}$. The effect of fibrinogen concentrate and fresh frozen plasma on the outcome of patients with acute traumatic coagulopathy: a quasi-experimental study. Am J Emerg Med. 2018;36(11):1947-50.

39. Curry N, Foley C, Wong H, Mora A, Curnow E, Zarankaite A, Hodge R, Hopkins V, Deary A, Ray J, et al. Early fibrinogen concentrate therapy for 
major haemorrhage in trauma (E-FIT 1): results from a UK multi-centre, randomised, double blind, placebo-controlled pilot trial. Crit Care. 2018; 22(1):164.

40. Schöchl H, Forster L, Woidke R, Solomon C, Voelckel W. Use of rotation thromboelastometry (ROTEM) to achieve successful treatment of polytrauma with fibrinogen concentrate and prothrombin complex concentrate. Anaesthesia. 2010;65(2):199-203.

41. Innerhofer $P$, Fries $D$, Mittermayr $M$, Innerhofer $N$, von Langen $D$, Hell $T$, Gruber G, Schmid S, Friesenecker B, Lorenz IH, et al. Reversal of traumainduced coagulopathy using first-line coagulation factor concentrates or fresh frozen plasma (RETIC): a single-centre, parallel-group, open-label, randomised trial. Lancet Haematol. 2017.

42. Nascimento B, Callum J, Tien H, Peng H, Rizoli S, Karanicolas P, Alam A, Xiong W, Selby R, Garzon AM, et al. Fibrinogen in the initial resuscitation of severe trauma (FiiRST): a randomized feasibility trial. Br J Anaesth. 2016; 117(6):775-82.

43. Hayakawa M, Maekawa K, Kushimoto S, Kato H, Sasaki J, Ogura H, Matsuoka T, Uejima T, Morimura N, Ishikura H, et al. Hyperfibrinolysis in severe isolated traumatic brain injury may occur without tissue hypoperfusion: a retrospective observational multicentre study. Crit Care. 2017;21(1):222.

44. Gando S, Nanzaki S, Kemmotsu O. Coagulofibrinolytic changes after isolated head injury are not different from those in trauma patients without head injury. J trauma. 1999;46(6):1070-6.

45. Kaufman HH, Moake JL, Olson JD, Miner ME, duCret RP, Pruessner JL, Gildenberg PL. Delayed and recurrent intracranial hematomas related to disseminated intravascular clotting and fibrinolysis in head injury. Neurosurgery. 1980;7(5):445-9.

46. Kaufman HH, Hui KS, Mattson JC, Borit A, Childs TL, Hoots WK, Bernstein DP, Makela ME, Wagner KA, Kahan BD, et al. Clinicopathological correlations of disseminated intravascular coagulation in patients with head injury. Neurosurgery. 1984;15(1):34-42.

47. Kushimoto S, Shibata Y, Yamamoto Y. Implications of fibrinogenolysis in patients with closed head injury. J Neurotrauma. 2003;20(4):357-63.

48. Geeraedts LM Jr, Demiral H, Schaap NP, Kamphuisen PW, Pompe JC, Frolke JP. 'Blind' transfusion of blood products in exsanguinating trauma patients. Resuscitation. 2007;73(3):382-8.

\section{Publisher's Note}

Springer Nature remains neutral with regard to jurisdictional claims in published maps and institutional affiliations.

Ready to submit your research? Choose BMC and benefit from:

- fast, convenient online submission

- thorough peer review by experienced researchers in your field

- rapid publication on acceptance

- support for research data, including large and complex data types

- gold Open Access which fosters wider collaboration and increased citations

- maximum visibility for your research: over $100 \mathrm{M}$ website views per year

At $\mathrm{BMC}$, research is always in progress.

Learn more biomedcentral.com/submissions 